Erratum

\title{
Erratum to "A Novel Nonsense Mutation of POU4F3 Gene Causes Autosomal Dominant Hearing Loss"
}

\author{
Chi Zhang, ${ }^{1,2}$ Mingming Wang, ${ }^{1,2}$ Yun Xiao, ${ }^{1,2}$ Fengguo Zhang, ${ }^{1,2}$ Yicui Zhou, ${ }^{1,2}$ \\ Jianfeng Li, ${ }^{1,2}$ Qingyin Zheng, ${ }^{3}$ Xiaohui Bai, ${ }^{1,2}$ and Haibo Wang ${ }^{1,2}$ \\ ${ }^{1}$ Department of Otorhinolaryngology Head and Neck Surgery, Shandong Provincial Hospital Affiliated to Shandong University, \\ Jinan, China \\ ${ }^{2}$ Shandong Provincial Key Laboratory of Otology, Jinan, China \\ ${ }^{3}$ Department of Otolaryngology-Head \& Neck Surgery, Case Western Reserve University, Cleveland, OH, USA \\ Correspondence should be addressed to Xiaohui Bai; sphbaixiaohui@163.com and Haibo Wang; whboto11@163.com \\ Received 20 February 2017; Accepted 5 March 2017; Published 18 June 2017 \\ Copyright (c) 2017 Chi Zhang et al. This is an open access article distributed under the Creative Commons Attribution License, \\ which permits unrestricted use, distribution, and reproduction in any medium, provided the original work is properly cited.
}

In the article titled "A Novel Nonsense Mutation of POU4F3 Gene Causes Autosomal Dominant Hearing Loss" [1], Dr. Xiaohui Bai should be listed as a corresponding author along with Haibo Wang.

\section{Reference}

[1] C. Zhang, M. Wang, Y. Xiao et al., "A novel nonsense mutation of POU4F3 gene causes autosomal dominant hearing loss," Neural Plasticity, vol. 2016, Article ID 1512831, 10 pages, 2016. 

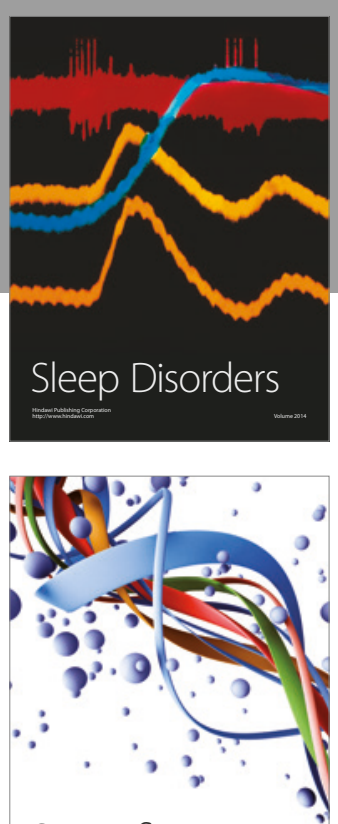

Scientifica
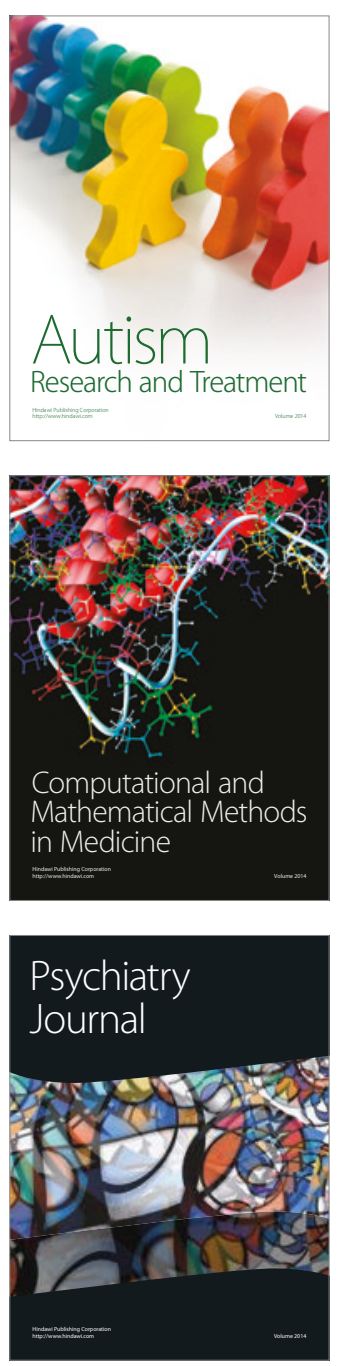
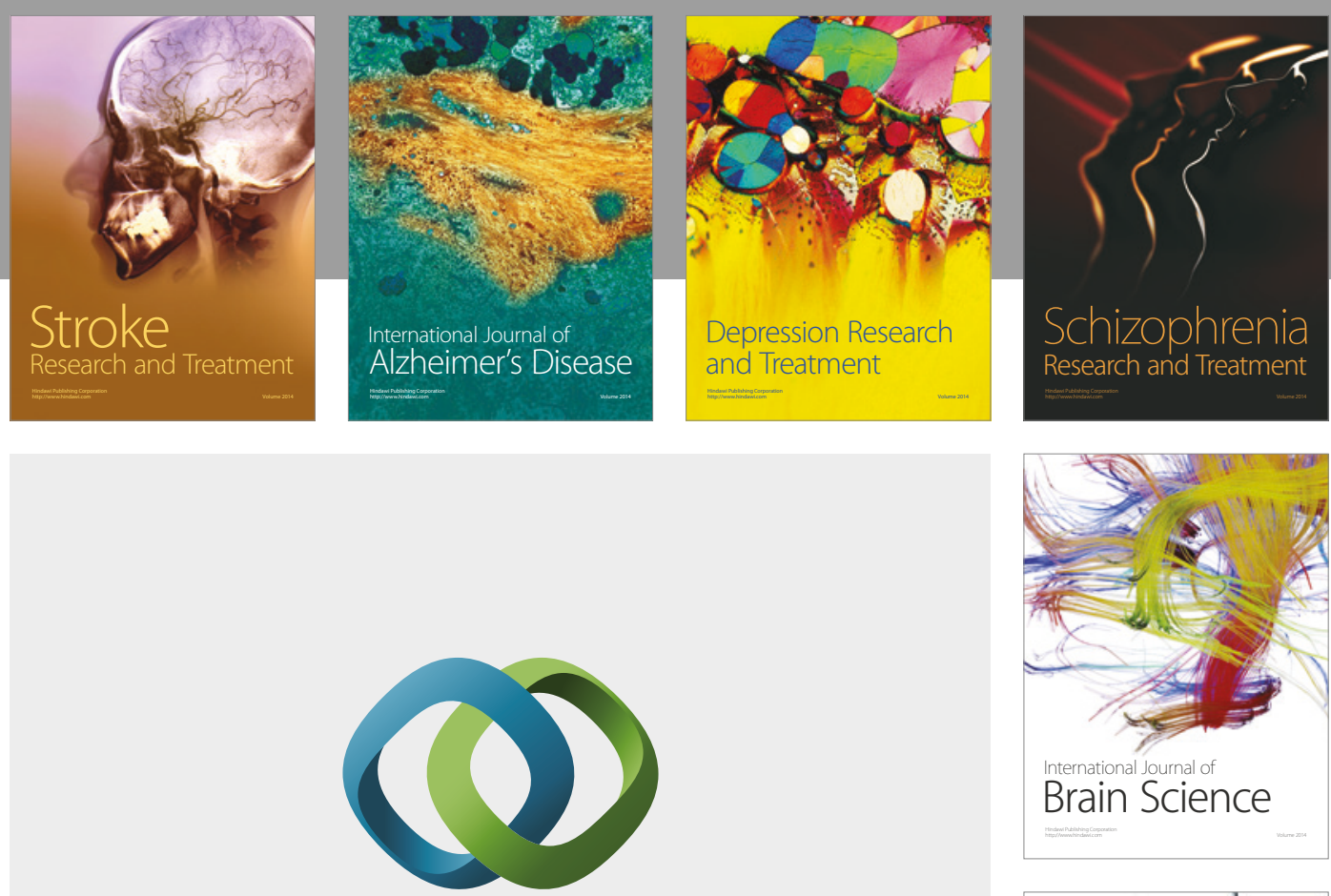

\section{Hindawi}

Submit your manuscripts at

https://www.hindawi.com
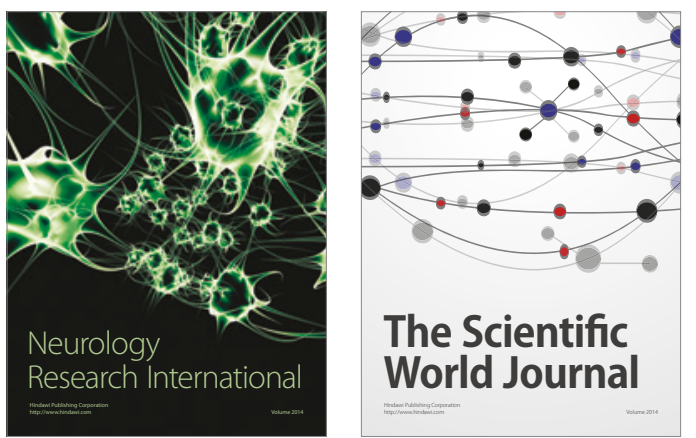

The Scientific World Journal

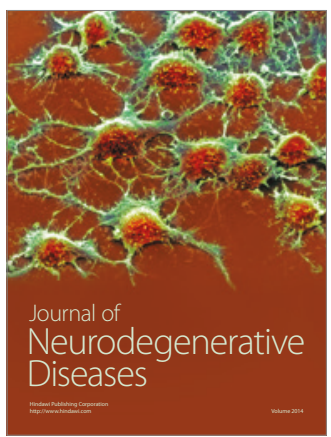

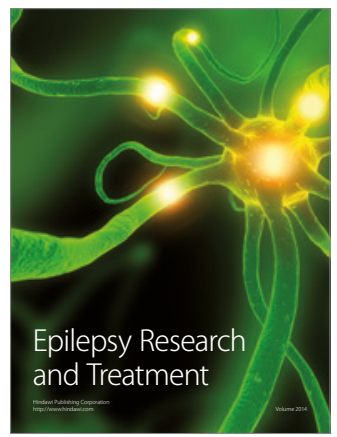

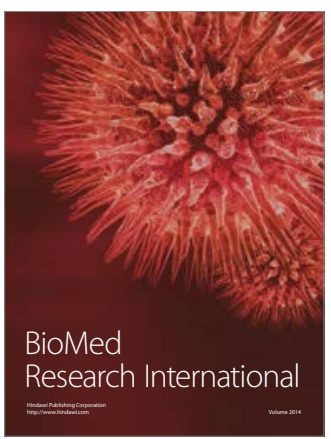

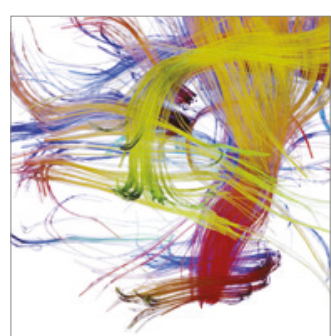

Brain Science

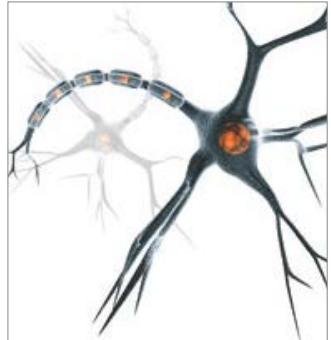

Neural Plasticity
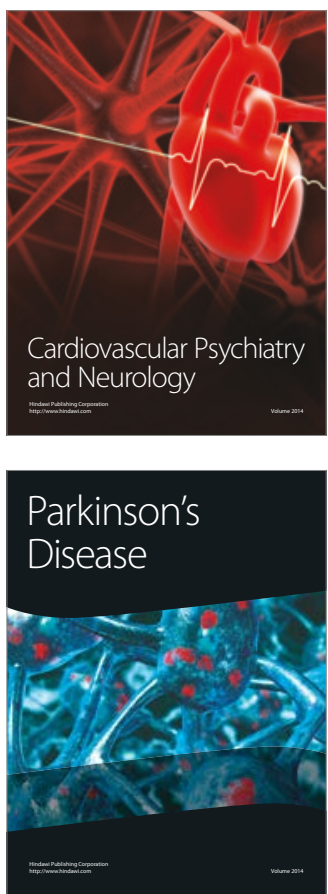